Research Article

\title{
Study on Performance of Mesoscopic Impactor Filters for Aerosol Removal
}

\author{
Wei Zhang (D), Fenglei Niu (D), Shiji Wang, Haonan Wang, and Zhangpeng Guo \\ Beijing Key Laboratory of Passive Safety Technology for Nuclear Energy, North China Electric Power University, \\ Beijing 102206, China \\ Correspondence should be addressed to Fenglei Niu; niufenglei@ncepu.edu.cn
}

Received 19 July 2019; Revised 28 October 2019; Accepted 9 November 2019; Published 26 November 2019

Academic Editor: Arkady Serikov

Copyright (c) 2019 Wei Zhang et al. This is an open access article distributed under the Creative Commons Attribution License, which permits unrestricted use, distribution, and reproduction in any medium, provided the original work is properly cited.

The mesoscopic impactor filter is designed to filtrate aerosols in the containment, which has not only high collection efficiency but also small flow resistance. In this paper, the influence of structural parameters and working parameters of the inertial impactor on collection performance is studied by the computational fluid dynamic (CFD) method. Under the small Reynolds number, the laminar model is used to simulate the continuous phase, and the discrete phase model (DPM) is used to track the trajectory of the particle. Based on the response surface methodology (RSM), the prediction model of collection efficiency and pressure drop is obtained, which will provide a reference for the design and manufacture of the filter in the future.

\section{Introduction}

After the nuclear accident in Three Mile Island, USA, some foreign research institutions have proposed a variety of technical measures and design requirements [1-4]. Furthermore, some specific methods and measures have been given to ensure the integrity of the containment when severe accident occurs. Once the integrity of the containment is threatened, it is a common design concept of international research institutions that radioactive aerosols in containment can be discharged outward by active pressure relief so that the pressure in the containment cannot exceed its loadbearing limit. However, if the exhaust gas is discharged directly without being filtered, it will inevitably cause radioactive contamination to the surrounding environment and residents. Therefore, the radioactive material in the exhaust gas must be filtered by a filter device installed on the pressure relief line to minimize the radioactivity of the aerosol so that the radioactivity of the containment gas is maintained at a low level within the legally permissible range.

At present, the filters mainly used in nuclear power plants are bubble-column filters, sand bed filters, high-efficiency air filters, metal fiber filters, and so on [5]. Through investigation and research, it was found that the bubblecolumn filter completes aerosol washing by an L-type venting tube submerged under the washing liquid; the sand bed filter traps aerosols through a special fine sand filter material; the high-efficiency filter is a disposable dry filter by using a multilayered filter material to collect aerosols; and the metal fiber filter filtrates the aerosol mainly by a multilayer filter made from stainless steel fiber [6, 7]. Although these kinds of filters can filtrate the radioactive aerosol in the containment, a large amount of radioactive waste is generated after filtration, which will cause new radioactive contamination and cannot purify the aerosol completely.

In order to solve this problem, a new filter which is designed based on the mesoscopic inertial impactor is proposed. In 1955, J. B. Wong first proposed the use of mesoscopic inertial impactor to filtrate aerosols [8]. In recent years, many scientists have devoted to the design and development of the inertial impactor [9-18]. Because of its simple structure, low flow resistance, and high-efficiency performance, the inertial impactor has been widely used to collect and monitor the aerosol particles. In our previous work, a T-type mesoscopic impactor filter has been proposed to collect aerosols (as shown in Figure 1) [7]. Although the impactor has high collection efficiency, there is a high flow 


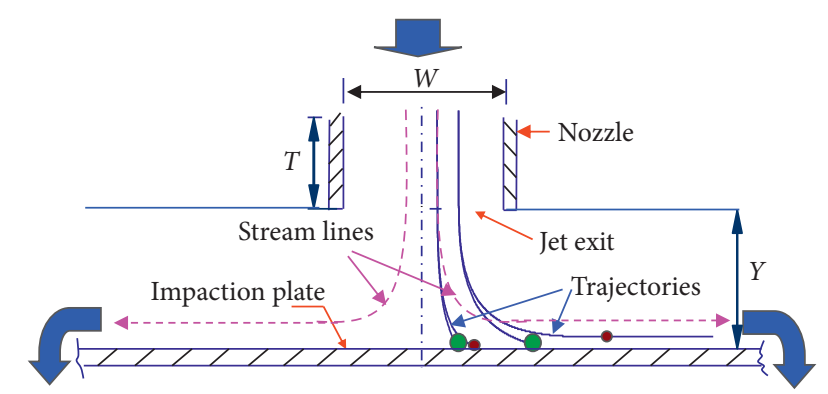

FIgURE 1: T-junction inertial impactor model ( $W$ stands for the inlet nozzle diameter, $T$ stands for the inlet nozzle height, and $Y$ stands for the outlet diameter).

resistance due to the small turning angle of the impactor. Based on which, a new mesoscopic impactor filter with high collection efficiency and low flow resistance introduced in this paper is invented. The effects of the inlet diameter, turning angle, pipe length, flow velocity, and particle diameter on the collection performance are studied by employing experimental design and numerical simulation. This method not only reduces the cost of studying these factors one by one but also provides a model to predict collection efficiency and pressure drop, which is helpful to the design and manufacture of filters in the future.

\section{Model Setup}

2.1. Filtration Principle and Model Development. For filtering radioactive contamination, the mesoscopic impactor filter studied in this paper is installed on the pressure relief line as a part of the filtered containment venting system. The filtration process is as follows: after the isolation valve of containment is opened in the late period of severe accident, the gas in the containment will be filtered through a filtered containment venting system. The filtered gas is monitored by the radiation monitoring system and then discharged into the atmosphere through the chimney. By reference to the relevant data, it can be known that when the containment begins to relieve pressure, the state of the aerosol in the containment is shown in Table 1 [19]. From the calculation, it can be seen that when the filtered containment venting system is turned on, the volume flow rate of the aerosol passing through the impactor is about $1120 \mathrm{~m}^{3} / \mathrm{h}$. Because of the high flow rate of aerosol in filtered containment venting systems, when severe accidents occur, the design of a whole inertial impactor filter based on this flow rate will not be conducive to the control of the experimental cost. Therefore, at the early stage of research, we designed and manufactured an inertial impactor (as shown in Figures 2(a) and 2(b)) at small flow rates $\left(1.5 \sim 5 \mathrm{~m}^{3} / \mathrm{h}\right)$ based on previous studies to verify the filtration performance of the impactor. Once this design is used in filtered containment venting systems, we will design a filter with enough surface area to reduce the pressure in the containment according to the flow rate of the airflow. However, in order to simplify the calculation, only a single inertial impactor is studied in this paper.

Conceptual illustrations of the basic building block of an inertial impactor are shown in Figure 2(c), in which $a$ stands
TABle 1: Aerosol properties in the containment of the Qinshan Nuclear Power Plant during severe accident.

\begin{tabular}{lc}
\hline Aerosol properties & Value \\
\hline Mass flow rate & $3.5 \mathrm{~kg} / \mathrm{s}$ \\
Temperature & $145^{\circ} \mathrm{C}$ \\
Pressure & $0.45 \mathrm{MPa}$ \\
Specific gravity & $3.4 \mathrm{~kg} / \mathrm{m}^{3}$ \\
Aerosol concentration & $0.1 \mathrm{~g} / \mathrm{m}^{3}$ \\
\hline
\end{tabular}

for pipe length, $b$ stands for the inlet diameter, $\theta$ stands for the turning angle, $V_{\mathrm{g}}$ stands for the inlet velocity, and $d$ stands for the particle diameter. An inertial impactor consists of an inlet, an outlet, and a wall part. When the aerosol particles enter the inertial impactor with airflow, the direction of the airflow suddenly changes when passing through the elbow. The aerosol particles with a large mass tend to follow the original trajectories due to the inertia effects [20] so that they cannot follow the airflow and collide with the wall, which is used for capture. The aerosol with small particles has good followability to the airflow and is easy to flow out with the airflow without being collected. It is easy to cause blockage of the flow channel by using a traditional filter. However, the mesoscopic impactor filter studied in this paper has an inlet diameter three orders of magnitude larger than the aerosol particle size, which significantly improve the airflow velocity and effectively reduce the frequency of blocking.

2.2. Initial Conditions and Boundary Conditions. In this work, the Stokes equation (N-S equation) and the continuity equation are built and solved by the DPM model. In the process of calculation and solution, according to the nuclear power plant accident conditions, the internal temperature of the impactor is set to $150^{\circ} \mathrm{C}$, and the internal gas-solid twophase pressure is set to $0.407 \mathrm{MPa}$ [21]. The aerosol in the containment of the nuclear power plant is a mixture and contains a large number of dense cladding materials, which are made from alloy. Therefore, the alloy particles are applicable in the calculation. Its density is 8030 times of the air density. After investigation, the effects of gravity, Brownian motion, drag, thermophoresis force, Saffman force, and pressure gradient force on the particles are considered [4].

In order to depict the inertial impactors' performance, totally 27 simulation cases with different geometry parameters (inlet diameter, pipe length, and turning angle) were studied. Commercial software ANSYS15.0 is used to solve the governing equations. Considering the accuracy and efficiency of the calculation, the sensitivity of the grid was analyzed for each geometry by using different mesh sizes with the collecting efficiency as an indicator. The particle orbital model is used to simulate the gas phase, particle phase, and the coupling between the two phases in this work. Before simulating particle motion, the inlet and the outlet of the impactor are set as an escape surface, and the wall surface is set as a trap surface. In addition, it is assumed that the particle velocity at the inlet is the same as the air velocity in the impactor. 


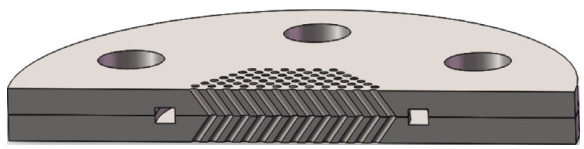

(a)

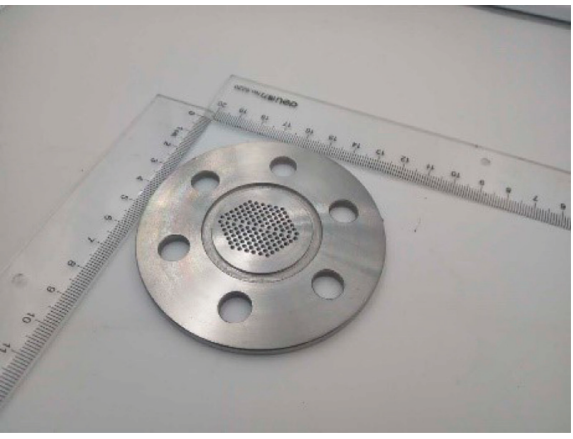

(b)

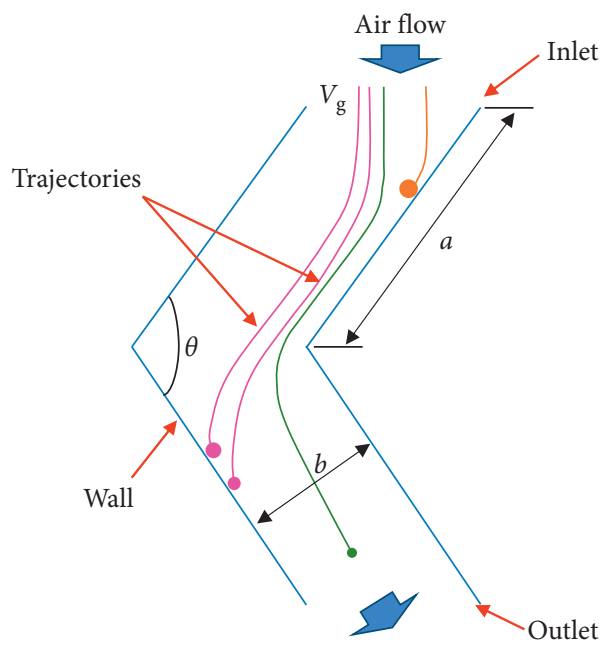

(c)

FIGURE 2: Inertial impactor model. (a) The cross-sectional structure of an experimental sample containing 126 mesoscopic impactors. (b) Photograph of the experimental sample fabricated in stainless steel. (c) Conceptual illustrations of the basic building block of the mesoscopic impactor.

\subsection{Comparison of Model Simulation with Experimental} Data. In the paper "Research on submicron particle sampler based on inertial impactor," Zhou Guangchao et al. [22] have measured the collection efficiency curve of the mesoscopic inertial impactor through experiments. In order to verify the accuracy of the simulation results, the simulation was carried out with the experimental parameters in [22]. The comparison between the calculated results and the experimental data is shown in Figure 3. It can be seen from the figure that calculations agree well with the published experiments. That means the simulation calculations in this paper can be used to simulate the collection efficiency of inertial impactors.

2.4. Response Surface Design. Response surface design is a commonly used data processing method in experimental design. Its working principle is to select the response surface equation according to the actual situation firstly and then estimate the response coefficient according to the least-squares method to obtaining the initial response

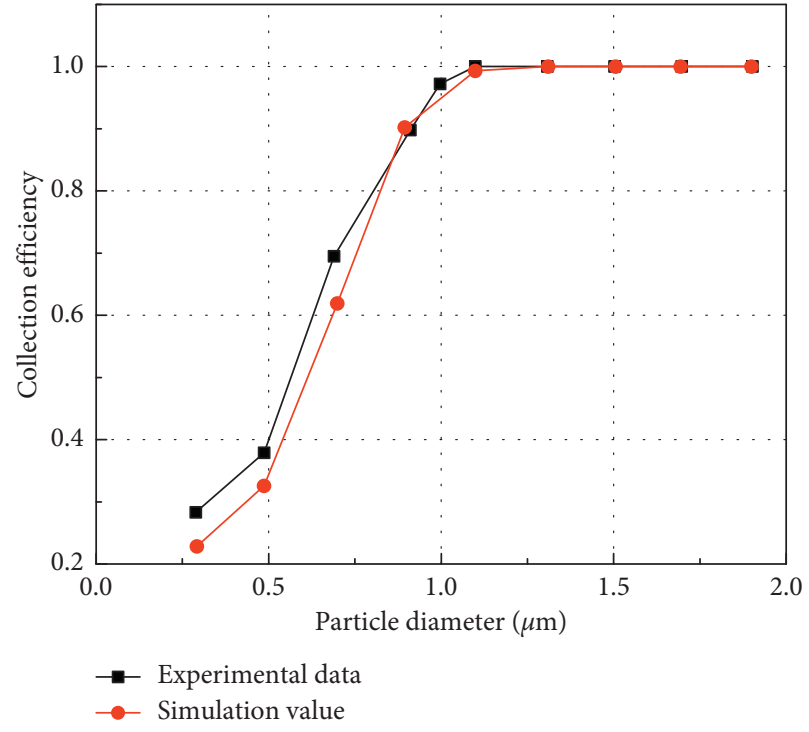

FIgURE 3: Collection efficiency curve of the designed particle sampler. 


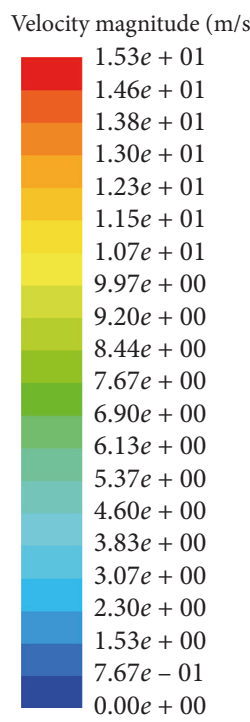

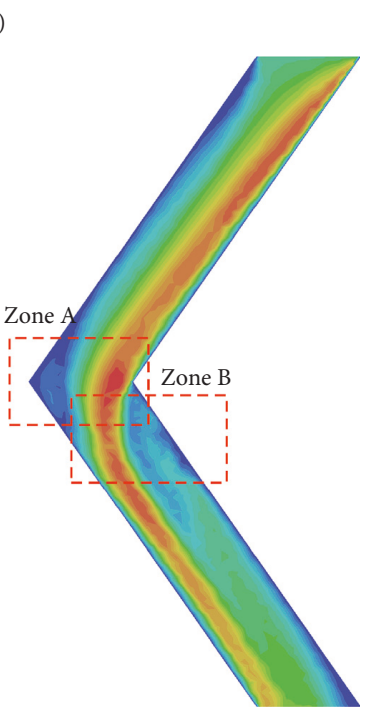

(a)

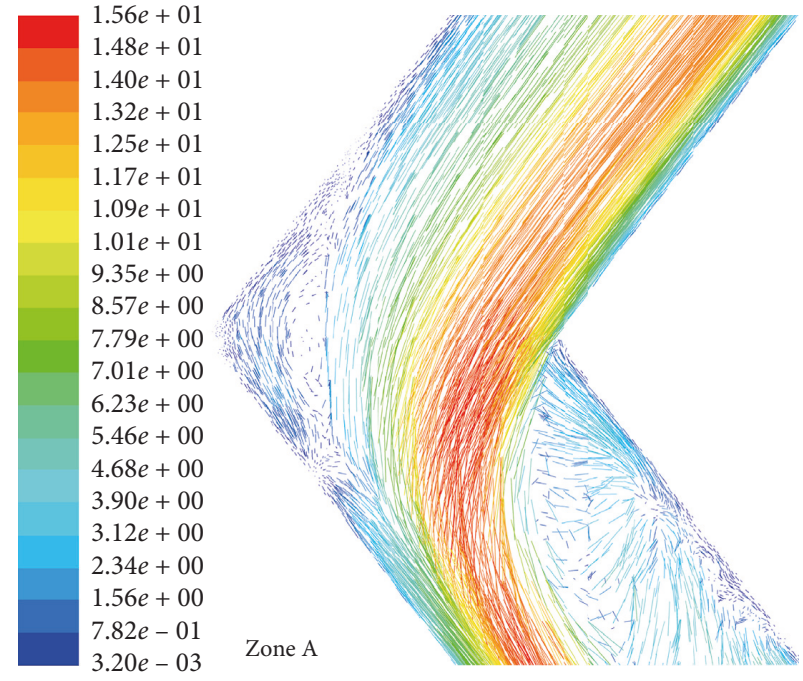

(b)
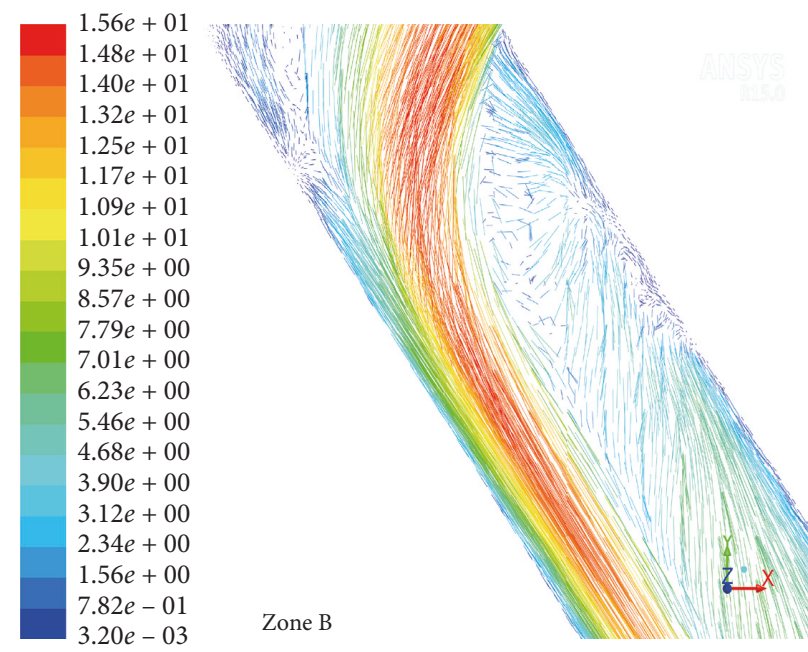

(c)

Figure 4: Airflow field in the impactor. (a) Velocity magnitude contour of the impactor; (b) velocity vectors of the recirculation zone A; (c) velocity vector of the recirculation zone $B$.

surface equation. In the end, based on the magnitude of the significance test value, the factors in the equation that have a significant influence on the objective function can be analyzed.

The response surface is adequately fitted by a secondorder polynomial model, as given in the following equation [23-25]:

$$
Y=\beta_{0}+\sum_{i=1}^{k} \beta_{i} x_{i}+\sum_{i=1}^{k} \beta_{i i} x_{i}^{2}+\sum_{i<j} \beta_{i j} x_{i} x_{j}+\varepsilon\left(x_{1}, x_{2}, \ldots, x_{k}\right),
$$

where $Y$ is the response defined as collection efficiency or pressure drop, $k$ is a variable, $\beta_{0}, \beta_{i}, \beta_{i i}$, and $\beta_{i j}$ are coefficients of the intercept, linear, square, and interaction effects, respectively, and $\varepsilon$ is the error.

\section{Results and Discussion}

3.1. Flow Field Analysis. In order to simplify and more accurately perform the simulations, it is assumed that the velocity of the discrete phase is the same as that of the continuous phase. The velocity magnitude contours and particle trajectories of the impactor with a turning angle of $110^{\circ}$, a pipe length of $5 \mathrm{~mm}$, and an inlet diameter of $1 \mathrm{~mm}$ are shown in Figures 4 and 5, respectively. As shown in Figure 4(a), under the effect of inertia, the aerosol flows close to the lower wall of the pipe, and particles are collected after impacting the wall. There are two recirculation zones formed in the pipeline. The velocity vectors in Figures 4(b) and 4(c) show the recirculation flow in zone $\mathrm{A}$ and zone $\mathrm{B}$, respectively. Verlaan [26] mentioned in his paper that the recirculation flow in the pipe reduces the flow path and significantly increased the air velocity of the main gas 


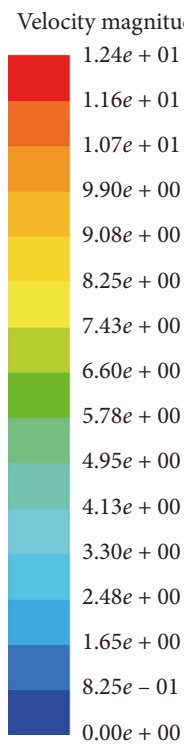

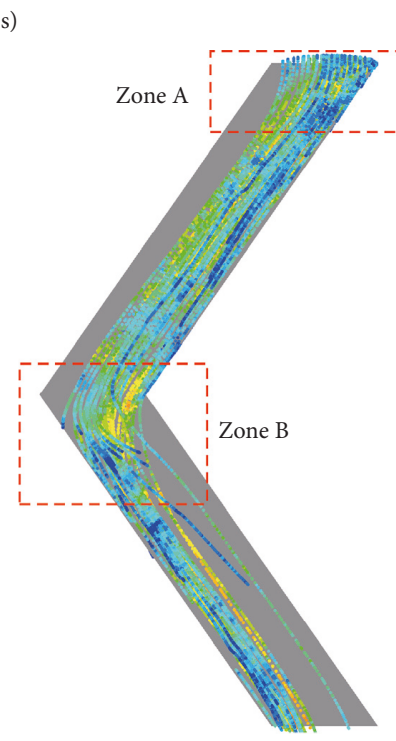

(a)

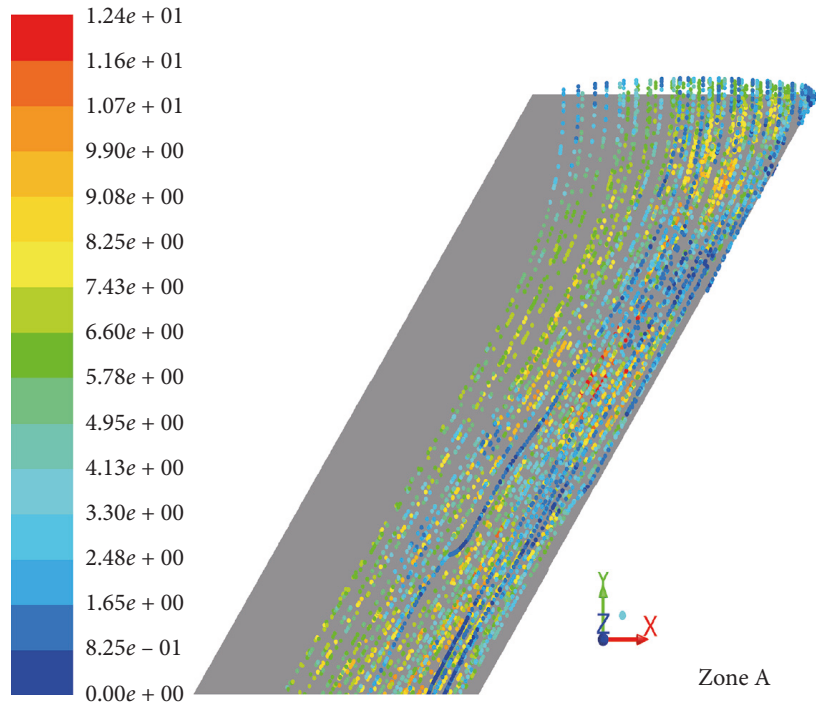

(b)

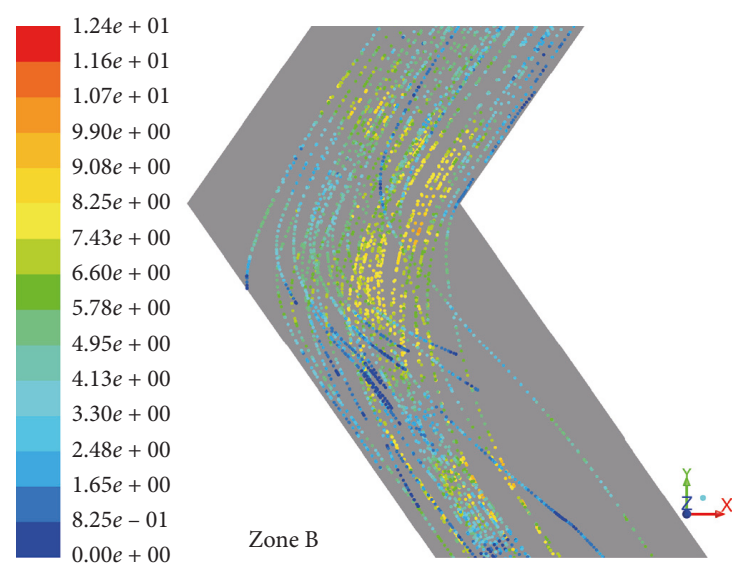

(c)

FIGURE 5: (a) Particle trajectories of the impactor; (b) partially enlarged view of the selected zone A; (c) partially enlarged view of the selected zone B.

stream, which is conducive to the improvement of collection efficiency. Figure 5(a) depicts the particle trajectories and the flow streamline of the particle with a diameter of $2 \mu \mathrm{m}$ in the inertial impactor. It can be inferred from Figure 5(b) that the airflow at the inlet changes direction for the first time. Due to the effect of inertia, the particles near the entrance wall are not easy to change the direction of movement, so they collide with the wall and are collected, while the particles far from the wall enter the elbow with airflow. When the direction of the airflow changes again, most of the particles are collected, while a small part of them flow out of the tube. Partially enlarged view of the selected zone B is shown in Figure 5(c).

3.2. Influence of Factors on Collection Efficiency. In the first step of this research, the effect of airflow velocity on the performance of the inertial impactor was investigated. The chosen impactor has a turning angle of $110^{\circ}$, a pipe length of $4 \mathrm{~mm}$, and an inlet diameter of $1 \mathrm{~mm}$. The collection efficiency curves of the inertial impactor at different velocities are shown in Figure 6(a). It can be seen that the collection efficiency increases as the velocity increases at the same particle diameter. At the inlet velocity of $8 \mathrm{~m} / \mathrm{s}$, particles larger than $1.5 \mu \mathrm{m}$ can be completely collected, while when the inlet velocity is $2 \mathrm{~m} / \mathrm{s}$, only particles greater than $4 \mu \mathrm{m}$ can be completely collected. It can be observed from the theoretical analysis that the greater the inlet velocity, the greater the inertial force. Therefore, at high inlet velocity, the collection efficiency of small particles is easy to reach $100 \%$.

The influence of the turning angle on collection efficiency at different particle diameters is demonstrated in Figure 6(b). The results show that the larger the turning angle, the lower the collection efficiency and the smoother the efficiency curve. This is because with the increase in the turning angle, the direction of the airflow becomes smoother. Therefore, the change in the direction of particle movement is decreased, and most of the particles flow out of the tube with the airflow. 


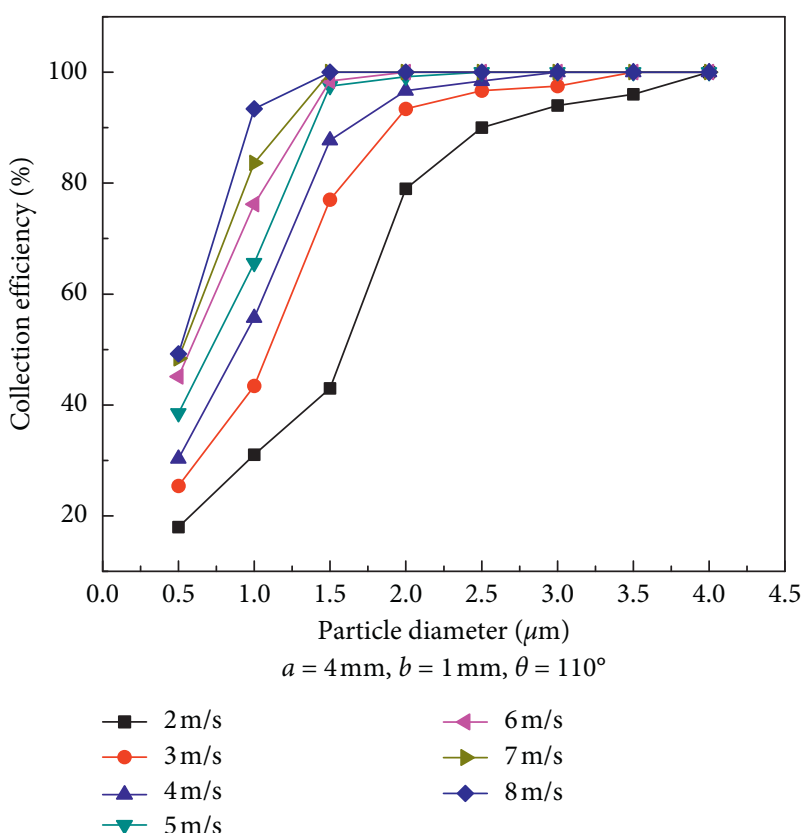

(a)

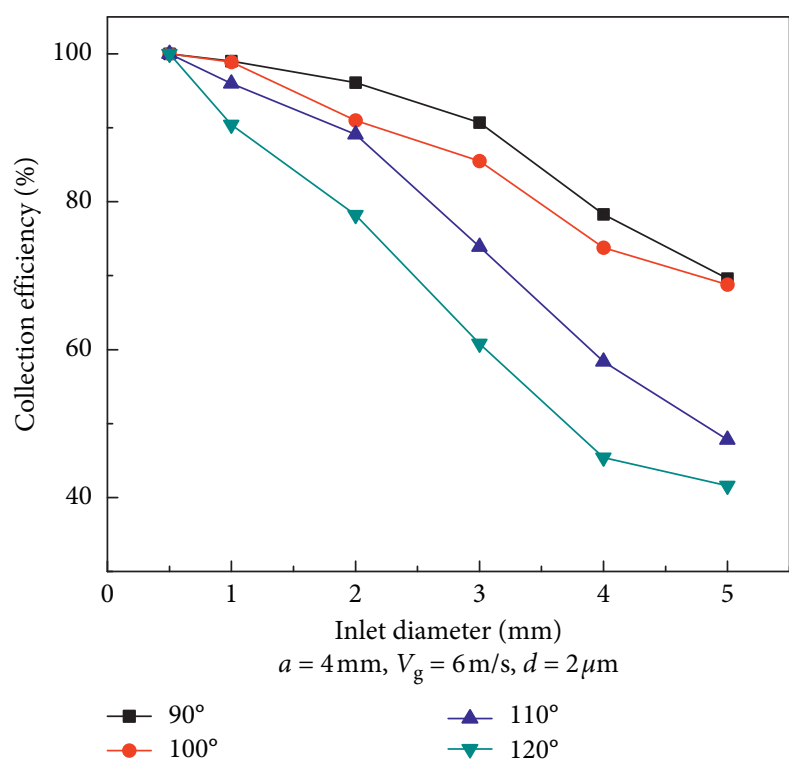

(c)

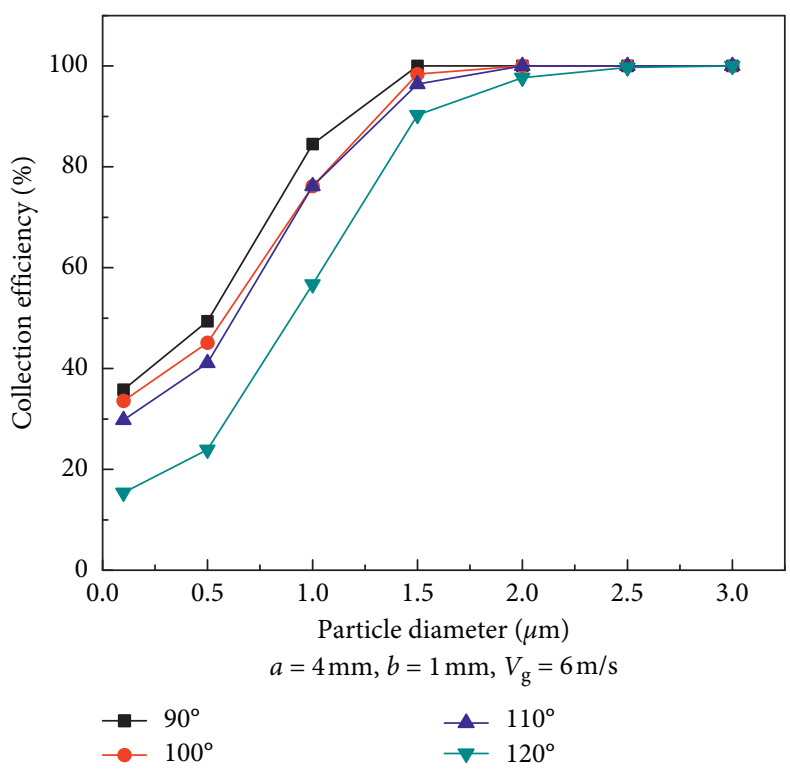

(b)

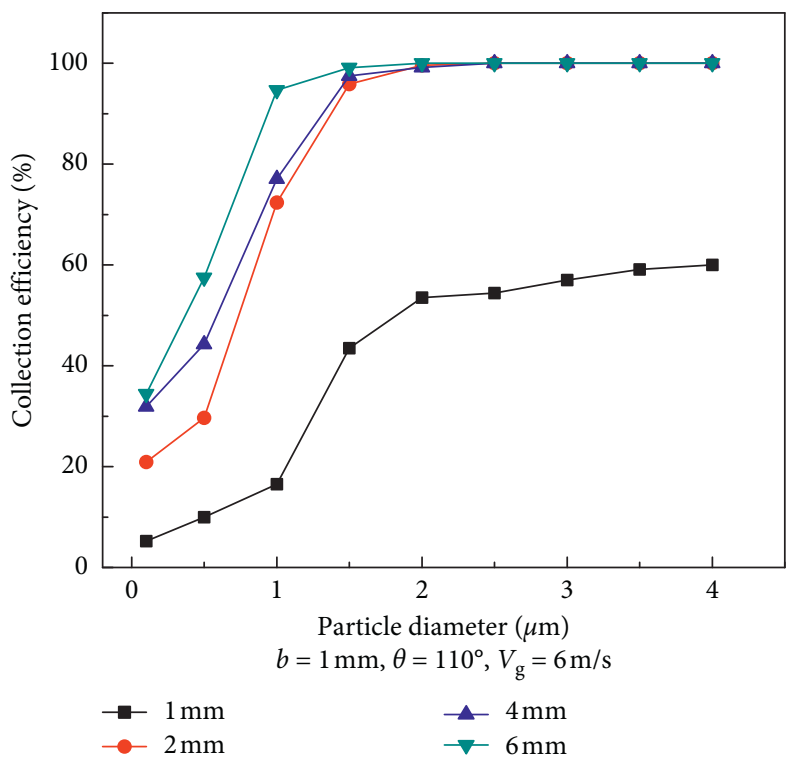

(d)

Figure 6: (a) The influence of inlet airflow velocity on collection efficiency; (b) the influence of turning angle on collection efficiency; (c) the influence of inlet diameter on collection efficiency; (d) the influence of pipe length on collection efficiency.

The influence of the inlet diameter on collection efficiency at different turning angles is shown in Figure 6(c). The results of the model with a turning angle of $110^{\circ}$ depicted that collection efficiency is continuously decreased from $100 \%$ to $47.8 \%$ when the inlet diameter varied from $0.5 \mathrm{~mm}$ to $5 \mathrm{~mm}$. It can be seen from the figure that as the inlet diameter increases, the collection efficiency decreases. The increased inlet diameter would extend the flow area of particles in the pipeline, and at the same time, the velocity direction of the airflow tends to be gentle. Therefore, the particles have good followability to the airflow and are easy to flow out with the gas stream without being collected.
Besides, the simultaneous increase in the turning angle and the inlet diameter enhances this effect.

Figure 6(d) displays the effect of pipe length on collection efficiency. All models have the same inlet diameter of $1 \mathrm{~mm}$. By increasing the pipe length from $1 \mathrm{~mm}$ to $6 \mathrm{~mm}$, the collection efficiency is gradually increased. It can be observed that the collection efficiency increases with the increase of pipe length. However, for large particles, when the pipe length exceeds twice the inlet diameter of the impactors, increasing the pipe length has very little effect on promoting collection efficiency. For example, the collection efficiency for particle diameter of $2 \mu \mathrm{m}$ at pipe length of $2 \mathrm{~mm}$ is nearly 


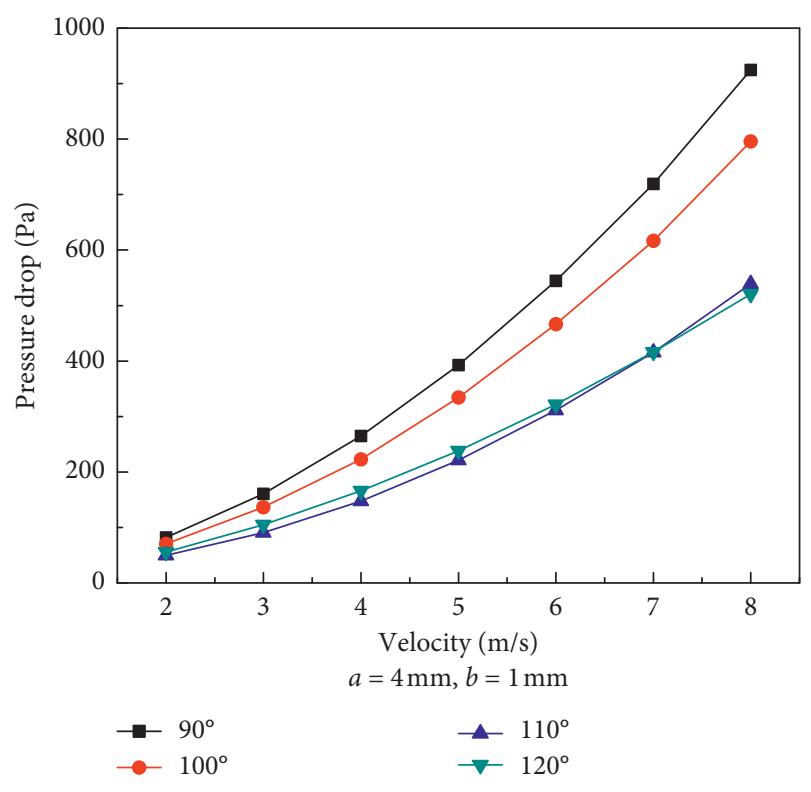

(a)

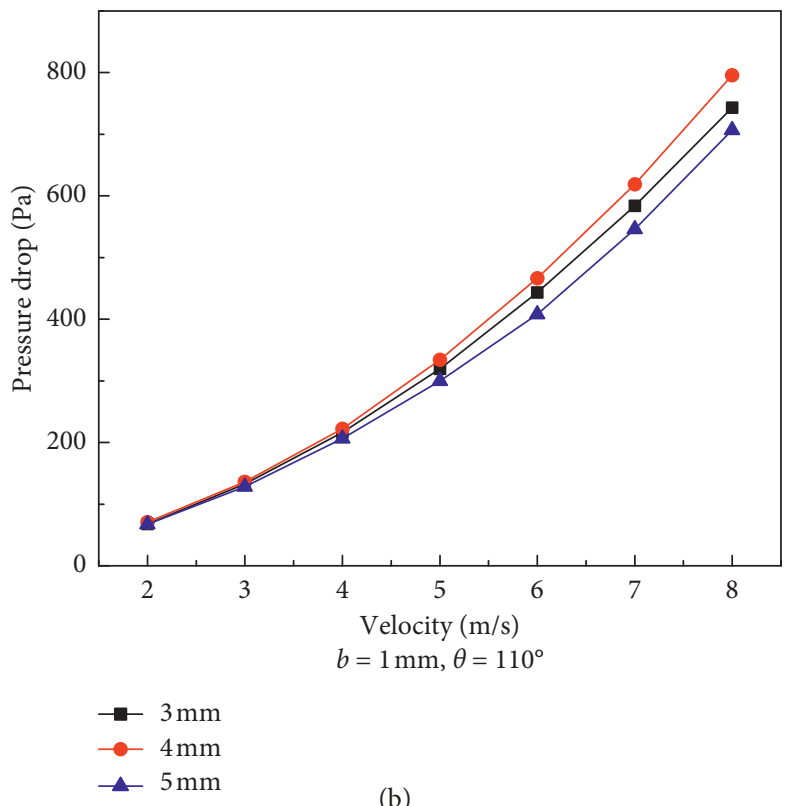

(b)

FIgURE 7: (a) The influence of turning angle on pressure drop; (b) the influence of pipe length on pressure drop.

$45.7 \%$ greater than that of $1 \mathrm{~mm}$, while the collection efficiency at pipe length of $4 \mathrm{~mm}$ is only $0.4 \%$ greater than that of $2 \mathrm{~mm}$.

3.3. Influence of Factors on Pressure Drop. Pressure drop is an important index to judge the performance of a filter. The filter used in the containment requires a low flow resistance to ensure the containment pressure relief following the nuclear accident. In this group of simulations, the effect of gas velocity, turning angle, and pipe length on pressure drop of the inertial impactor has been investigated.

The influence of the turning angle on pressure drop is shown in Figure 7(a). It is clear that the difference of pressure drop between the model with a turning angle of $110^{\circ}$ and $120^{\circ}$ is not obvious, while it has sufficient influence on the impactor with a turning angle less than $110^{\circ}$. In addition, the flow velocity has a great influence on the pressure drop. As the flow velocity increases, the pressure drop is continuously increased.

Figure 7(b) displays the effect of pipe length on the pressure drop. The turning angle of the model is $110^{\circ}$ and the inlet diameter is $1 \mathrm{~mm}$. It shows that pipe length has little effects on pressure drop with flow velocity less than $5 \mathrm{~m} / \mathrm{s}$, so the fluctuation of pressure drop curve can be ignored within a narrow pipe length range.

3.4. Analysis of Response Surface Model. As mentioned above, the inlet diameter, pipe length, turning angle, particle diameter, and airflow velocity will affect the filtration performance, but the influence of various factors on the collection efficiency and pressure drop is different. In order to get the influence of various factors, 41 models involving 5 physical factors were designed by the BoxBehnken method to reduce the calculation time. All those
TABLE 2: Test results of 41 cases with various parameters.

\begin{tabular}{|c|c|c|c|c|c|c|c|}
\hline Number & $\begin{array}{c}b \\
(\mathrm{~mm})\end{array}$ & $\begin{array}{c}a \\
(\mathrm{~mm})\end{array}$ & $\begin{array}{c}\theta \\
\left({ }^{\circ}\right)\end{array}$ & $\begin{array}{c}d \\
(\mu \mathrm{m})\end{array}$ & $\begin{array}{c}V_{\mathrm{g}} \\
(\mathrm{m} / \mathrm{s})\end{array}$ & $\begin{array}{l}\mathrm{CE} \\
(\%)\end{array}$ & $\Delta P$ \\
\hline 1 & 1 & 2 & 110 & 2.5 & 5 & 100 & 241.8 \\
\hline 2 & 2 & 2 & 110 & 2.5 & 8 & 34.1 & 678.5 \\
\hline 3 & 2 & 4 & 130 & 4.0 & 5 & 96.6 & 137.5 \\
\hline 4 & 2 & 6 & 110 & 2.5 & 8 & 99.4 & 631.9 \\
\hline 5 & 1 & 4 & 110 & 4.0 & 5 & 100 & 25 \\
\hline 6 & 3 & 6 & 110 & 2.5 & 5 & 89.9 & 294.4 \\
\hline 7 & 2 & 4 & 110 & 4.0 & 2 & 98.9 & 50.8 \\
\hline 8 & 2 & 4 & 90 & 2.5 & 2 & 91.9 & 81.8 \\
\hline 9 & 2 & 4 & 130 & 2.5 & 8 & 93.5 & 334.2 \\
\hline 10 & 2 & 4 & 130 & 2.5 & 2 & 19.9 & 30.7 \\
\hline 11 & 2 & 4 & 110 & 1.0 & 8 & 79 & 634.1 \\
\hline 12 & 2 & 2 & 110 & 4.0 & 5 & 36.9 & 260.4 \\
\hline 13 & 3 & 4 & 110 & 2.5 & 8 & 45.3 & 757.2 \\
\hline 14 & 3 & 2 & 110 & 2.5 & 5 & 14.2 & 272.6 \\
\hline 15 & 1 & 4 & 90 & 2.5 & 5 & 100 & 415.3 \\
\hline 16 & 3 & 4 & 110 & 2.5 & 2 & 15.5 & 49.4 \\
\hline 17 & 2 & 2 & 110 & 1.0 & 5 & 12.3 & 267.8 \\
\hline 18 & 1 & 4 & 110 & 1.0 & 5 & 89.6 & 250 \\
\hline 19 & 2 & 6 & 110 & 4.0 & 5 & 100 & 255.6 \\
\hline 20 & 2 & 6 & 130 & 2.5 & 5 & 94.9 & 149.6 \\
\hline 21 & 2 & 2 & 90 & 2. & 5 & 25.7 & 470.4 \\
\hline 22 & 1 & 4 & 130 & 2.5 & 5 & 100 & 152.7 \\
\hline 23 & 3 & 4 & 90 & 2.5 & 5 & 31.1 & 564.1 \\
\hline 24 & 3 & 4 & 110 & 4.0 & 5 & 50.4 & 289.2 \\
\hline 25 & 1 & 4 & 110 & 2.5 & 8 & 100 & 564.8 \\
\hline 26 & 2 & 4 & 110 & 1.0 & 2 & 9.8 & 50.8 \\
\hline 27 & 2 & 2 & 110 & 2.5 & 2 & 16.6 & 45 \\
\hline 28 & 1 & 4 & 110 & 2.5 & 2 & 95.5 & 56.2 \\
\hline 29 & 2 & 2 & 130 & 2.5 & 5 & 27.9 & 136.4 \\
\hline 30 & 1 & 6 & 110 & 2.5 & 5 & 100 & 250 \\
\hline 31 & 2 & 6 & 110 & 2.5 & 2 & 88.9 & 50.8 \\
\hline 32 & 2 & 4 & 110 & 4.0 & 8 & 100 & 626.1 \\
\hline 33 & 3 & 4 & 130 & 2.5 & 5 & 28.1 & 147.7 \\
\hline 34 & 2 & 4 & 90 & 4.0 & 5 & 100 & 457.7 \\
\hline
\end{tabular}


TABle 2: Continued.

\begin{tabular}{lccccccc}
\hline Number & $\begin{array}{c}b \\
(\mathrm{~mm})\end{array}$ & $\begin{array}{c}a \\
(\mathrm{~mm})\end{array}$ & $\begin{array}{c}\theta \\
\left({ }^{\circ}\right)\end{array}$ & $\begin{array}{c}d \\
(\mu \mathrm{m})\end{array}$ & $\begin{array}{c}V_{\mathrm{g}} \\
(\mathrm{m} / \mathrm{s})\end{array}$ & $\begin{array}{c}\mathrm{CE} \\
(\%)\end{array}$ & $\Delta P$ \\
\hline 35 & 2 & 4 & 110 & 2.5 & 5 & 98 & 250.4 \\
36 & 2 & 4 & 90 & 2.5 & 8 & 98.8 & 1214.6 \\
37 & 3 & 4 & 110 & 1.0 & 5 & 12.5 & 294.2 \\
38 & 2 & 4 & 130 & 1.0 & 5 & 15.5 & 138.5 \\
39 & 2 & 6 & 90 & 2.5 & 5 & 98.2 & 496.6 \\
40 & 2 & 4 & 90 & 1.0 & 5 & 30.5 & 460 \\
41 & 2 & 6 & 110 & 1.0 & 5 & 30.5 & 250.4 \\
\hline
\end{tabular}

models are simulated in the same condition as defined before. Calculation results as well as initial parameters are listed in Table 2.

With the response surface methodology, the relationship between collection efficiency, pressure drop, and various factors is obtained. We can obtain the filtration performance of the impactor under different working conditions by calculation.

The following equations describe the effects of different parameters on separation efficiency and pressure drop, respectively:

$$
\begin{aligned}
\mathrm{CE}= & -349.05-33.9 b+34.10 a+6.40 \theta+50.70 d-6.40 V_{\mathrm{g}} \\
& +9.50 a b-0.04 b \theta+4.6 b d+2.10 b V_{\mathrm{g}}-0.03 a \theta \\
& +3.70 a d-0.30 a V_{\mathrm{g}}+0.10 \theta d+0.28 \theta V_{\mathrm{g}}-3.78 d V_{\mathrm{g}} \\
& -13.30 b^{2}-5.40 a^{2}-0.04 \theta^{2}-9.90 d^{2}-1.33 V_{\mathrm{g}}^{2}, \\
\Delta P= & 535.30+104.40 b+4.30 a-19.50 \theta+2.02 d \\
& +355.10 V_{\mathrm{g}}+1.70 a b-1.90 b \theta-0.83 b d+16.35 b V_{\mathrm{g}} \\
& -0.08 a \theta+1.05 a d-2.18 a V_{\mathrm{g}}+0.01 \theta d \\
& -3.45 \theta V_{\mathrm{g}}-0.94 d V_{\mathrm{g}}+12.73 b^{2}+1.2 a^{2}+0.14 \theta^{2} \\
& -0.43 d^{2}+10.82 V_{\mathrm{g}}^{2} .
\end{aligned}
$$

Table 3 shows the results of the variance analysis of the response surface model for collection efficiency. The statistical results in Table 3 show that the influence of pipe length, inlet diameter, and particle diameter on the quadratic response surface model is extremely significant $(P<0.001)$. The $F$ values given in Tables 3 and 4 are test statistics used to determine whether an item is associated with a response. The larger the $F$ value is, the more significant the influence of this factor is [27]. Therefore, according to the magnitude of $F$ value in Table 3, the order of influence of parameters on collection efficiency is inlet diameter $>$ pipe length $>$ particle diameter $>$ airflow velocity $>$ turning angle in the studied parameter norm. Figure $8(a)$ is a response surface for the effect of inlet diameter and pipe length on collection efficiency. It can be seen from the figure that as the inlet diameter increases, the collection efficiency gradually decreases; for a certain value of the inlet diameter, the longer the pipe length, the higher the collection efficiency, and the change of trend becomes more and more gentle. However, in
TABLE 3: Analysis of variance of collection efficiency.

\begin{tabular}{lcccc}
\hline Sources & Sum of squares & Mean square & $F$ value & $P$ value \\
\hline Model & 47767.70 & 2388.39 & 8.14 & $<0.0001$ \\
$b$ & 15506.48 & 15506.48 & 52.83 & $<0.0001$ \\
$a$ & 11777.68 & 11777.68 & 40.13 & $<0.0001$ \\
$\theta$ & 622.50 & 622.50 & 2.12 & 0.1608 \\
$d$ & 10155.60 & 10155.60 & 34.60 & $<0.0001$ \\
$V_{\mathrm{g}}$ & 2838.23 & 2838.23 & 9.67 & 0.0055 \\
$b * a$ & 1432.62 & 1432.62 & 4.88 & 0.0390 \\
$b * \theta$ & 2.25 & 2.25 & $7.666 E-003$ & 0.9311 \\
$b * d$ & 189.06 & 189.06 & 0.64 & 0.4316 \\
$b * V_{\mathrm{g}}$ & 160.02 & 160.02 & 0.55 & 0.4689 \\
$a * \theta$ & 7.56 & 7.56 & 0.026 & 0.8741 \\
$a * d$ & 504.00 & 504.00 & 1.72 & 0.2049 \\
$a * V_{\mathrm{g}}$ & 12.25 & 12.25 & 0.042 & 0.8402 \\
$\theta * d$ & 33.64 & 33.64 & 0.11 & 0.7385 \\
$\theta * V_{\mathrm{g}}$ & 1112.22 & 1112.22 & 3.79 & 0.0658 \\
$d * V_{\mathrm{g}}$ & 1159.40 & 1159.40 & 3.95 & 0.0607 \\
$b^{2}$ & 542.82 & 542.82 & 1.85 & 0.1890 \\
$a^{2}$ & 1470.30 & 1470.30 & 5.01 & 0.0367 \\
$\theta^{2}$ & 684.25 & 684.25 & 2.33 & 0.1425 \\
$d^{2}$ & 1550.08 & 1550.08 & 5.28 & 0.0325 \\
$V_{\mathrm{g}}^{2}$ & 445.16 & 445.16 & 1.52 & 0.2324 \\
\hline
\end{tabular}

TABLE 4: Analysis of variance of pressure drop.

\begin{tabular}{lcccc}
\hline Source & Sum of squares & Mean square & $F$ value & $P$ value \\
\hline Model & $2.472 E+006$ & $1.236 E+005$ & 53.55 & $<0.0001$ \\
$b$ & 31773.06 & 31773.06 & 13.76 & 0.0014 \\
$a$ & 2.56 & 2.56 & $1.109 E-003$ & 0.9738 \\
$\theta$ & $5.377 E+005$ & $5.377 E+005$ & 232.94 & $<0.0001$ \\
$d$ & 3705.77 & 3705.77 & 1.61 & 0.2197 \\
$V_{\mathrm{g}}$ & $1.579 E+006$ & $1.579 E+006$ & 683.88 & $<0.0001$ \\
$b * a$ & 46.24 & 46.24 & 0.020 & 0.8889 \\
$b * \theta$ & 5913.61 & 5913.61 & 2.56 & 0.1252 \\
$b * d$ & 12100.00 & 12100.00 & 5.24 & 0.0331 \\
$b * V_{\mathrm{g}}$ & 9920.16 & 9920.16 & 4.30 & 0.0513 \\
$a * \theta$ & 42.25 & 42.25 & 0.018 & 0.8937 \\
$a * d$ & 39.69 & 39.69 & 0.017 & 0.8970 \\
$a * V_{\mathrm{g}}$ & 686.44 & 686.44 & 0.30 & 0.5916 \\
$\theta * d$ & 0.42 & 0.42 & $1.830 E-004$ & 0.9893 \\
$\theta * V_{\mathrm{g}}$ & $1.719 E+005$ & $1.719 E+005$ & 74.48 & $<0.0001$ \\
$d * V_{\mathrm{g}}$ & 16.00 & 16.00 & $6.931 E-003$ & 0.9345 \\
$b^{2}$ & 2.84 & 2.84 & $1.232 E-003$ & 0.9723 \\
$a^{2}$ & 289.88 & 289.88 & 0.13 & 0.7268 \\
$\theta^{2}$ & 12151.68 & 12151.68 & 5.26 & 0.0327 \\
$d^{2}$ & 760.09 & 760.09 & 0.33 & 0.5725 \\
$V_{\mathrm{g}}^{2}$ & 32050.59 & 32050.59 & 13.88 & 0.0013 \\
\hline
\end{tabular}

the process of design and production, an appropriate increase in pipe length can increase collection efficiency, but it will increase the difficulty in processing.

The results of the variance analysis of the response surface model for pressure drop are shown in Table 4. It can be inferred that the model is mainly influenced by element terms of three linear terms $\left(b, \theta\right.$, and $\left.V_{\mathrm{g}}\right)$, two interactive terms ( $b d$ and $\theta V_{\mathrm{g}}$ ), and two squared terms $\left(\theta^{2}\right.$ and $\left.V_{\mathrm{g}}^{2}\right)$. In addition, as seen from the table, $a$ and $d$ almost have little influence on the pressure drop. Figure 8(b) gives the interactive influence of turning angle and airflow velocity on 


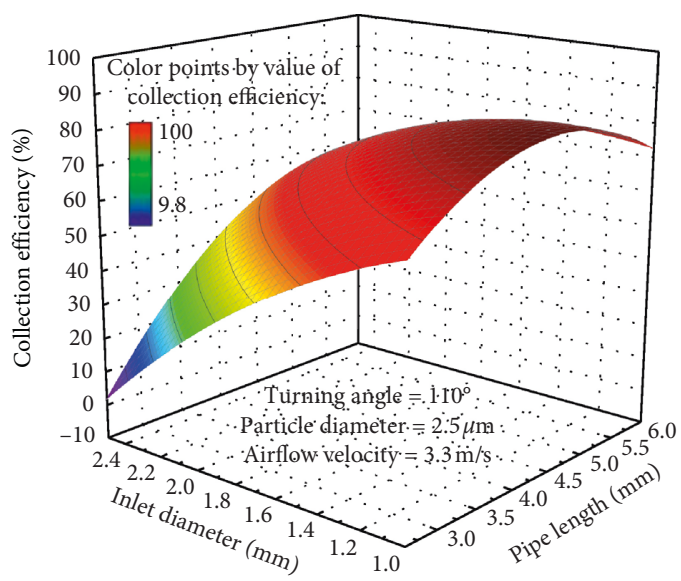

(a)

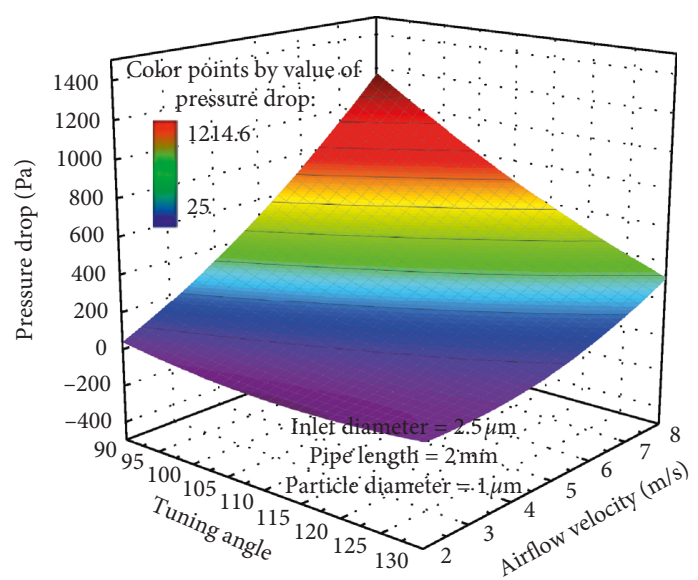

(b)

FIGURE 8: (a) Collection efficiency versus inlet diameter and pipe length; (b) pressure drop versus turning angle and airflow velocity.

pressure drop. It can be seen that when the airflow speed is small, the pressure drop is maintained at a lower level. As the gas flow velocity increases, the value of pressure drop gradually increases, and the smaller the turning angle, the more obvious the pressure drop increases. Therefore, for high airflow speed, the turning angle can be appropriately increased to reduce the pressure drop of the impactor.

\section{Conclusion}

In this work, the effects of structural parameters and working parameters of the inertial impactor on collection performance were investigated by simulation. In the simulation, the gas-solid two-phase flow in the impactor was simulated by the Euler-Lagrangian method. The particle motion is simulated by solving the motion equations of each discrete phase. In addition, in order to find out the influence degree of each factor on the filtration performance, the response surface methodology was used to analyze the influence of each parameter on collection efficiency and pressure drop. The following conclusions can be obtained through analysis:

(1) The pipe length, inlet diameter, and particle diameter have a significant impact on collection efficiency. Decreasing inlet diameter and increasing airflow velocity can improve collection efficiency. For the inertial impactor with the same structure, the larger the particle diameter, the higher the collection efficiency. Furthermore, when the pipe length is less than twice the inlet diameter of the impactor, increasing the pipe length can significantly improve the collection efficiency.

(2) The effect of inlet diameter, turning angle, and airflow velocity on pressure drop is significant. Pressure drop can be obviously decreased by increasing the turning angle at high flow velocity. It can be summarized as a universal method to design or optimize the inertial impactor.
(3) In this paper, the formulas for calculating collection efficiency and pressure drop are obtained by the response surface methodology. The formulas can fully reflect the influence of the impactor structure and working parameters on collection performance, which will be helpful to impactor design and manufacture.

Compared with previous works, it is the first time to design and simulate a 3D impactor model to investigate the influence of structural parameters and working parameters on the aerosol collection performance, which is meaningful for designing and optimizing the inertial impactor. However, this paper only studied the case of one unit of the inertial impactor. In the future, multiple impactors in parallel will be studied for different flow rates. In addition, compared with the traditional filter, the mesoscopic inertial impactor has a larger aperture in a single flow channel. As long as the filter surface area is designed properly, the filter will not cause serious blockage in a short time, or excessively hinder the pressure relief of the containment. Under the long-term working conditions, the impactor may be blocked, which could be the subject of future work.

\section{Data Availability}

The data used to support the findings of this study are included within the article.

\section{Conflicts of Interest}

The authors declare that there are no conflicts of interest regarding the publication of this paper.

\section{Acknowledgments}

This research was supported by the National Natural Science Foundation of China (Grant nos. 11635005 and 11705058) and the Fundamental Research Funds for the Central Universities (2018ZD10). 


\section{References}

[1] T. Sato and Y. Kojima, "Variations of a passive safety containment for a BWR with active and passive safety systems," Nuclear Engineering and Design, vol. 237, no. 1, pp. 74-86, 2007.

[2] B. De Boeck, "Prevention and mitigation measures to ensure containment integrity," Nuclear Engineering and Design, vol. 209, no. 1-3, pp. 147-154, 2001.

[3] W. Reim and D. Hurlebaus, "Protection of the containment of the twin BWR KRB II plant against overpressure failure during severe accidents," in Proceedings of the Containment of Nuclear Reactors Seminar, pp. 321-335, Netherlands, 1995.

[4] G. Kessler, "Requirements on future containments to avoid evacuation and relocation outside the plant," in Proceedings of the International Symposium on Global Environment and Nuclear Energy Systems, pp. 33-38, UK, 1995.

[5] D. Jacquemain, Status Report on Filtered Containment Venting, Committee on the Safety of Nuclear Installations, JT03360082, 2014.

[6] R. Arunkumar, K. U. Hogancamp, M. S. Parsons et al., "Highefficiency particulate air filter test stand and aerosol generator for particle loading studies," Review of Scientific Instruments, vol. 78, 2007.

[7] F. Niu, X. Du, H. Qi, M. Yi, and X. Yang, "Modeling analyses of radioactive aerosol flow and collection in mesoscopic impactor filters," Progress in Nuclear Energy, vol. 88, pp. 147-155, 2016.

[8] J. B. Wong, W. E. Ranz, and H. F. Johnstone, "Inertial impaction of aerosol particles on cylinders," Journal of Applied Physics, vol. 26, no. 2, pp. 244-249, 1955.

[9] A. R. McFarland, C. A. Ortiz, and R. W. Bertch Jr., "Particle collection characteristics of a single-stage dichotomous sampler," Environmental Science \& Technology, vol. 12, no. 6, pp. 679-682, 1978.

[10] S. J. Lee, P. Demokritou, P. Koutrakis, and J. M. DelgadoSaborit, "Development and evaluation of personal respirable particulate sampler (PRPS)," Atmospheric Environment, vol. 40, no. 2, pp. 212-224, 2006.

[11] X. Chen, Y. Feng, W. Zhong, B. Sun, and F. Tao, "Numerical investigation of particle deposition in a triple bifurcation airway due to gravitational sedimentation and inertial impaction," Powder Technology, vol. 323, pp. 284-293, 2018.

[12] C. Sioutas, S. T. Ferguson, J. M. Wolfson, H. Ozkaynak, and P. Koutrakis, "Inertial collection of fine particles using a highvolume rectangular geometry conventional impactor," Journal of Aerosol Science, vol. 28, no. 6, pp. 1015-1028, 1997.

[13] S. K. Zaripov, O. V. Solov'eva, and S. A. Solov'ev, "Inertial deposition of aerosol particles in a periodic row of porous cylinders," Aerosol Science and Technology, vol. 49, no. 6, pp. 400-408, 2015.

[14] C. Misra, M. Singh, S. Shen, C. Sioutas, and P. M. Hall, "Development and evaluation of a personal cascade impactor sampler (PCIS)," Journal of Aerosol Science, vol. 33, no. 7, pp. 1027-1047, 2002.

[15] H. Haokai, Z. Chaohe, and Z. Haibo, "Numerical investigation on non-steady-state filtration of elliptical fibers for submicron particles in the "Greenfield gap" range," Journal of Aerosol Science, vol. 114, pp. 263-275, 2017.

[16] S. Singh, B. K. Sapra, A. Khan, P. K. Kothalkar, and Y. S. Mayya, "Development of a variable configuration cascade impactor for aerosol size distribution measurement," Atmospheric Environment, vol. 44, no. 6, pp. 795-802, 2010.

[17] T.-W. Cheon, J.-Y. Lee, J.-Y. Bae, and S.-J. Yook, "Enhancement of collection efficiency of an inertial impactor using an additional punched impaction plate," Aerosol and Air Quality Research, vol. 17, no. 10, pp. 2349-2357, 2017.

[18] M. Ihalainen, T. Lind, J. Ruusunen et al., "Experimental study on bounce of submicron agglomerates upon inertial impaction," Powder Technology, vol. 268, pp. 203-209, 2014.

[19] Z. Zhou, "Reactor containment decompression and filtration in Qin Shan NPP phase II," Master's thesis, Shanghai Jiaotong University, Shanghai, China, 2007.

[20] X. Zhang, W. Zhang, M. Yi et al., "High-performance inertial impaction filters for particulate matter removal," Scientific Reports, vol. 8, p. 4757, 2018.

[21] G. Lin, AP1000 System and Equipment, Atomic Energy Press, USA, Version 1, 2008.

[22] G. Zhou, Y. Zhao, J. Han, C. Feng, and H. Huang, "Research on submicron particle sampler based on inertial impactor," Chinese Journal of Scientific Instrument, vol. 31, pp. 13811386, 2010.

[23] E. Narimani and S. Shahhoseini, "Optimization of vane mist eliminators," Applied Thermal Engineering, vol. 31, pp. 188193, 2011.

[24] J. Zhao, B. Jin, and Z. Zhong, "Study of the separation efficiency of a demister vane with response surface methodology," Journal of Hazardous Materials, vol. 147, pp. 363-369, 2007.

[25] F. Kavousi, Y. Behjat, and S. Shahhosseini, "Optimal design of drainage channel geometry parameters in vane demister liquid-gas separators," Chemical Engineering Research and Design, vol. 91, pp. 1212-1222, 2013.

[26] C. J. Verlaan, Performance of Novel Mist Eliminators, Ph.D. Thesis, Delft University of Technology, Delft, Netherlands, 1991.

[27] X. Zhao, Experimental Design Method, Science Press, Beijing, China, 2005. 

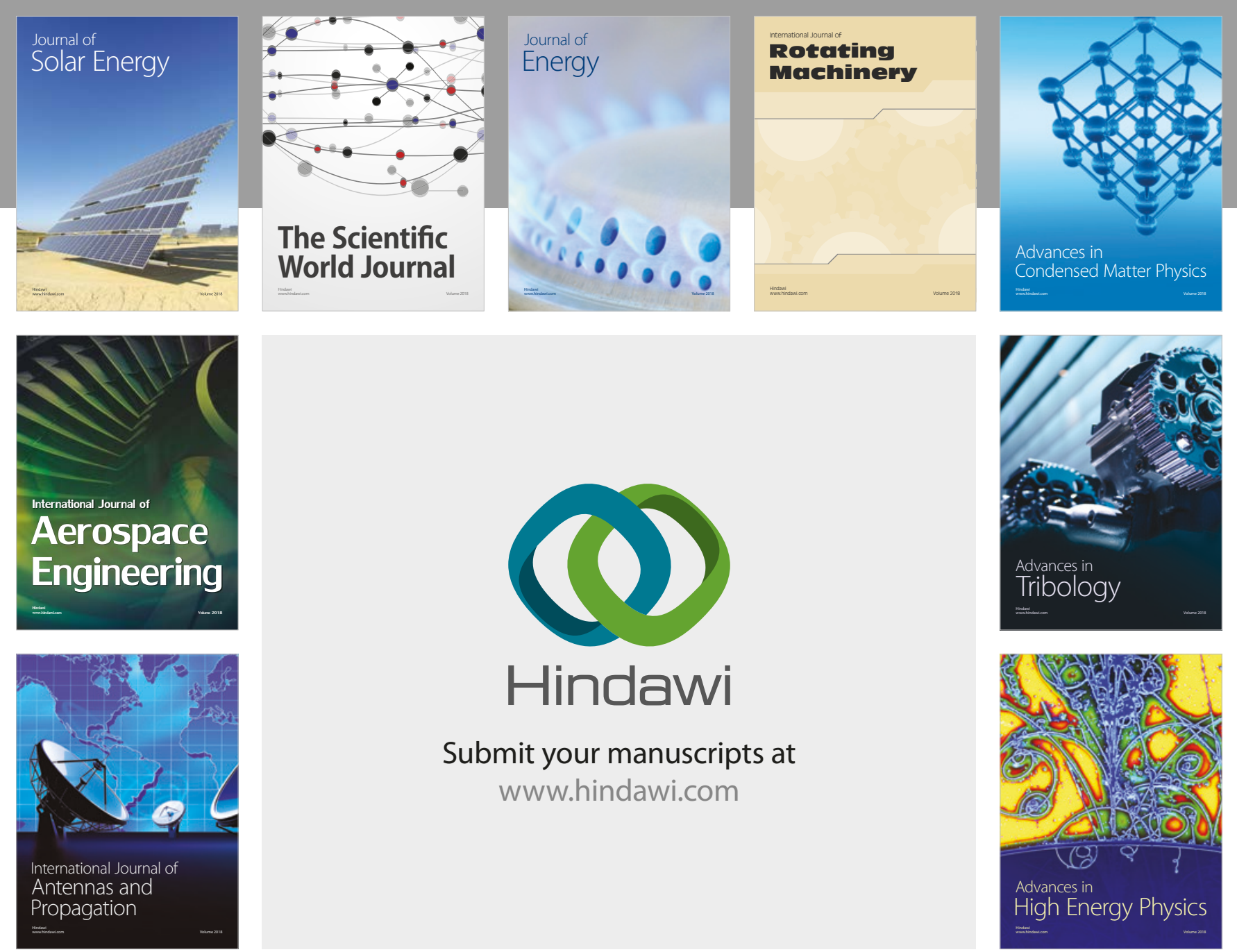

Submit your manuscripts at

www.hindawi.com
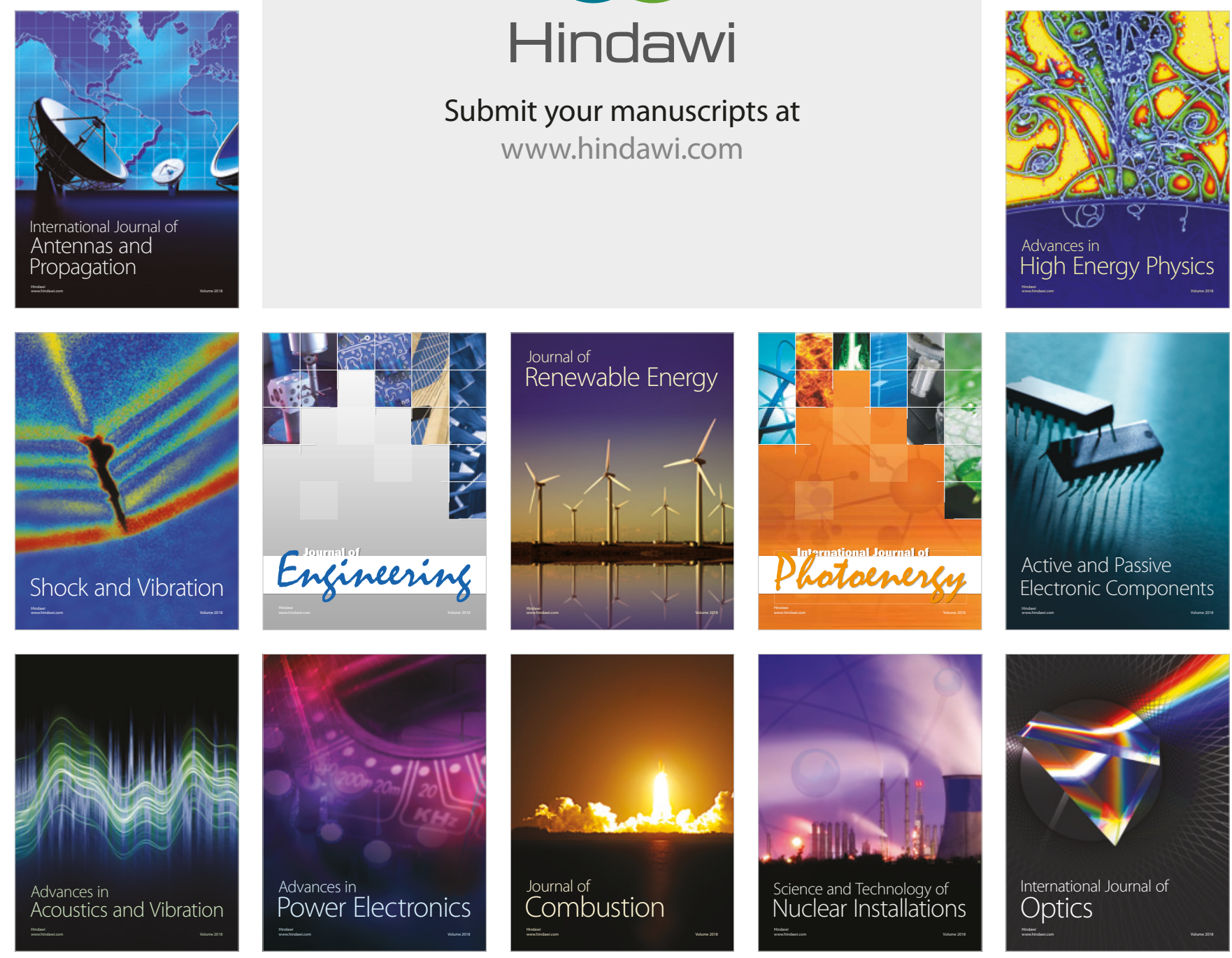